\title{
Evaluation of Facial Proportions and Their Association with Thumbprint Patterns among Hausa Ethnic Group
}

\author{
Lawan Hassan Adamu, ${ }^{1}$ Samuel Adeniyi Ojo, ${ }^{2}$ Barnabas Danborno, ${ }^{3}$ \\ Sunday Samuel Adebisi, ${ }^{3}$ and Magaji Garba Taura ${ }^{1}$ \\ ${ }^{1}$ Department of Anatomy, Faculty of Basic Medical Sciences, Bayero University, PMB 3011, Kano, Kano State, Nigeria \\ ${ }^{2}$ Department of Veterinary Anatomy, Faculty of Veterinary Medicine, Ahmadu Bello University, Zaria, PMB 1045, \\ Samaru Zaria, Kaduna State, Nigeria \\ ${ }^{3}$ Department of Human Anatomy, Faculty of Medicine, Ahmadu Bello University, Zaria, PMB 1045, Samaru Zaria, \\ Kaduna State, Nigeria
}

Correspondence should be addressed to Lawan Hassan Adamu; alhassan.ana@buk.edu.ng

Received 26 July 2016; Revised 13 November 2016; Accepted 16 November 2016; Published 19 January 2017

Academic Editor: Santos Alonso

Copyright (C) 2017 Lawan Hassan Adamu et al. This is an open access article distributed under the Creative Commons Attribution License, which permits unrestricted use, distribution, and reproduction in any medium, provided the original work is properly cited.

Background. Evolutionary forces such as founder effect resulted in reproductive isolation and reduced genetic diversity may have led to ethnic variation in the facial appearance and other features like fingerprints pattern. Aim. To determine the pattern of facial proportion based on neoclassical facial canon. The associations between facial proportions and thumbprint patterns were also investigated. Subject and Methods. A total of 534 subjects of 18-25 years of age participated. Direct sensing and photographs methods were used to determine fingerprint and facial features, respectively. Fisher's Exact test was used to test for association between variables. Results. It was observed that in both males and females there was no (0\%) occurrence of classical canon of facial proportion. There was also no association between sex and facial proportions. A significant association was found in between thumbprint patterns and vertical class III neoclassical facial proportion only when the frequency of both left and right thumbprint patterns was considered a single entity. There is no significant association between the thumbprint patterns of the right and left thumbs with vertical horizontal facial proportions in male and female participants. It was observed that right and left thumbs have more tendency of significance with facial proportion in males and females, respectively. Conclusion. Fingerprint pattern and its associated features may be controlled by a different mechanism such that the two may correlate differently with other features as the case may be with facial features.

\section{Introduction}

The human sculptures produced in ancient Greece were derived from proportions that followed established rules or "canons" [1]. These rules were incorporated to be the "neoclassical canons" for the human face by Renaissance artists. These canons were based on the assumption that certain fixed ratios existed between different parameters of a harmonious face. Subsequently, these canons were adopted by medical artists, anatomists, and aesthetic surgeons and continue to be used to date [2,3]. Farkas was the first investigator to test the applicability of neoclassical facial canons by studying samples of 6, 12, and 18-year-old North American Caucasians [2].
Applicability of these canons was also tested on several other population groups such as the African Americans [4], Turkish [5], and Vietnamese, Thai [3], Chinese [3, 6], and Southern Chinese [7].

Evolutionary forces such as founder effect may result in reproductive isolation and reduced genetic diversity that led to ethnic variation in the facial appearance and other features like fingerprints pattern. It was also suggested that through, sexual selection, individuals with an attractive facial profile may have been more likely to reproduce and pass on such traits to subsequent generations [8]. Population characterization and differentiation using dermatoglyphics features like fingerprints have also been considered as a 
useful marker within the domain of biological anthropology $[9,10]$. The first step in fingerprint analysis was the identification of its pattern. Several authors reported variation in frequency/percentage of the fingerprint patterns in order to establish sex-specific and interethnic variations.

But prediction a biometric feature from another was a challenging research topic. However, prediction of face characteristics from only fingerprints was considered as an interesting and attractive idea for applications [11]. It was found that there was extensive literature on fingerprint identification and face recognition [12, 13]. Some of the scientists focused on analyzing the similarities in fingerprint minutiae patterns and facial variables in identical twins [14]. Consequently, this similarity supports the idea that there might be some relationships among fingerprints and faces. Nevertheless several studies have evaluated facial anthropometric of features different racial groups with emphases on neoclassical facial canon and its variant. But such attempt is scanty or absent among Hausa ethnic groups. Determination of the relationship between various anthropological variables was reported to be one of the important practices in the field of human biology. However, the association between thumbprint patterns and facial proportions receives less attention among Hausa ethnic group. Even among other population, the anthropological approach to establishing the relationship is often neglected. The objectives of the study were to determine the frequency of facial proportions based on neoclassical canon and also to determine the association between the facial proportions and thumbprints patterns in male and female Hausas.

\section{Materials and Methods}

2.1. Study Area. The language over time has been used as one of the markers of ethnic differentiation. From a historical point of view, the Hausa people have been referred to as Hausawa, Haoussa, Ausa, Habe, and Mgbakpa. In the whole of the sub-West African region, they constitute one of the single largest ethnic groups. They are located on a large scale in the Sahelian areas of northern Nigeria and the southeastern Niger and spread across other African countries [15]. The study was conducted in one original Hausa state, Kano state of Nigeria (Figure 1). Kano is the most populous state in Nigeria, with about 9,383,682 million people at the 2006 Nigerian census [16].

2.2. Subjects. A total of 534 subjects comprising 398 males and 136 females participated in the study; however, for sex differences analyses in facial proportion, 147 males and 136 females were involved. Any subject who is Hausas up to the level of grandfather, apparently healthy, whose thumbs and face were free from any inflammation, deformity, or pathological changes and within the age range of $18-25$ years, was included in the study and males subjects with excessive facial hair which obscures some of the facial landmarks. Any subject who declined his/her informed consent and outside the inclusion criteria was also excluded from the study. Before the commencement of the research, ethical approval was obtained from the Ethical Committee of Kano State Hospital Management Board. Informed consent was obtained from the participants and person whose photograph appears in the study.

2.3. Methodology. A direct sensing fingerprints capturing method using live scan was used. The participants were asked to clean their thumb to remove any dirt that may be associated with the skin ridges. The thumb was then placed on the fingerprint sensor (digital persona) (Figure 2). After capturing a thumbprint, the type of finger (thumb), sex (male or female), side of the finger (left or right), and unique code of the (questionnaire code) of the participants were saved with each thumbprint. The fingerprints were classified into any of the three basic patterns, namely, arches, whorls, and loops (Figure 2).

To obtain the photographs individuals were asked to sit and looked directly at the camera in front of them [17], keeping an upright and normal posture, with both arms free along the body. This position corresponds to Broca's Natural Head Position [18]. Behind the subject was placed a white screen to standardize the background. The camera was placed on a tripod stand (WT3570, China) to standardize the distance $(100 \mathrm{~cm})$ between it and the subject, as well as adjusting the camera according to sitting height of the subject. The captured images were uploaded to a personal computer and stored in jpeg format for processing and analyses. The linear distances, after correct placement of facial landmarks (Figure 3, Table 1), were measured using customized software developed using Microsoft visual basic (version 6) programming language. The linear distances were used to obtain proportion and classify the proportions into seven neoclassical facial canon and its variants (Table 3 ) as proposed by Farkas et al. [2, 4]. A factor of 0.45 obtained by dividing actual size measurements with actual pixel measurements was used to maintain the real size measurement from the photographs.

Standard anatomical landmarks [19-21] were recognized for measurement of linear distances (Table 2). These linear distances were used to determine the facial proportion.

2.4. Assessment of Measurement Error and Data Analyses. Precision of measurements was determined using

$$
\text { Absolute TEM }=\sqrt{\sum \frac{d i^{2}}{2 n}}
$$

where $\sum d^{2}$ is summation of deviations (the difference between the 1st and 2nd measurements) raised to the second power; $n$ is number of volunteers measured; and $i$ is the number of deviations

The absolute TEM was expressed as percentages as follows:

$$
\text { Relative TEM }=\frac{\text { Absolute TEM }}{\text { VAV }} \times 100,
$$

where VAV is variable average value; this is the arithmetic mean of the mean between both measurements obtained 


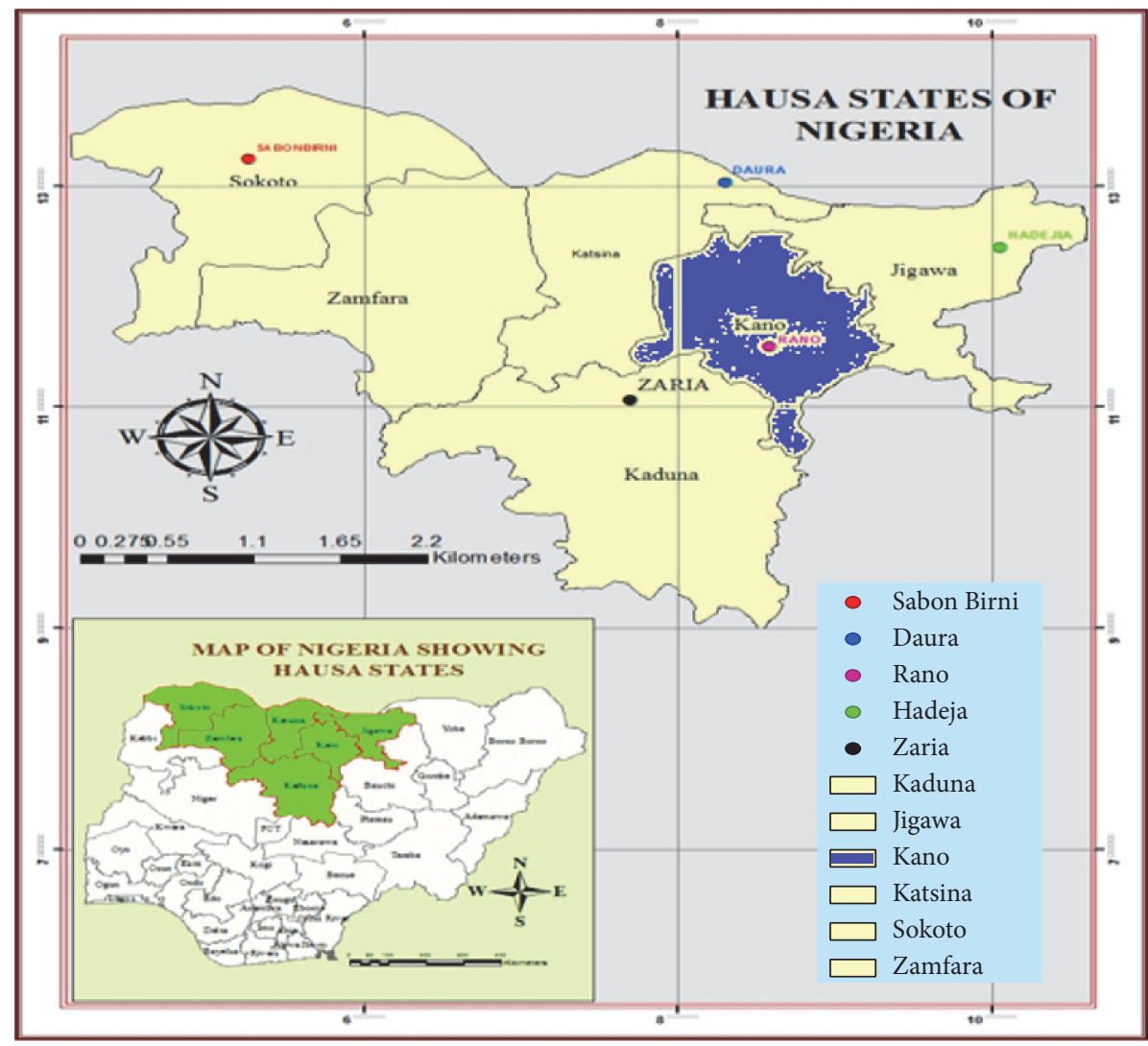

FIGURE 1: Map of Hausa States of Nigeria.
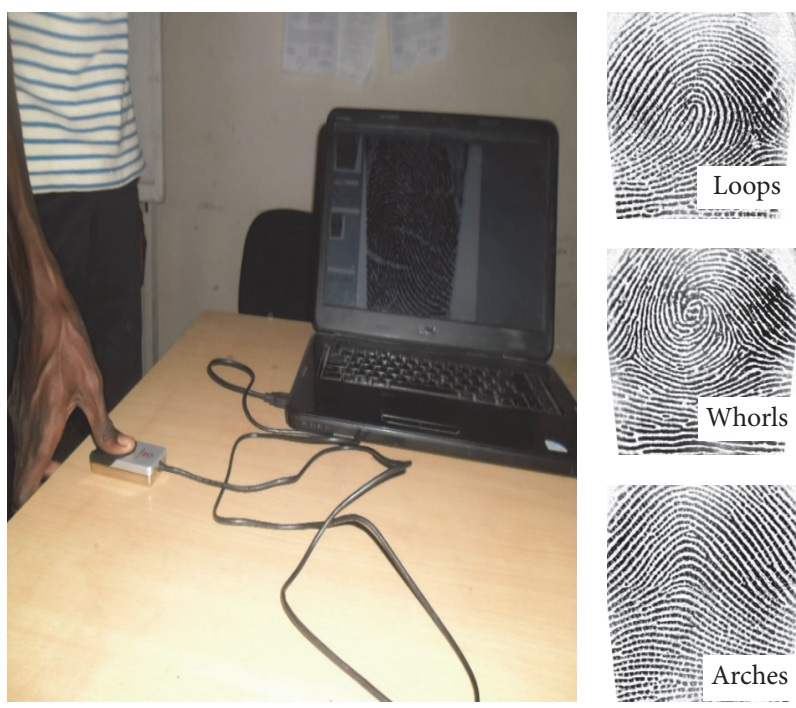

FIGURE 2: Fingerprints capturing and classification image.

(1st and 2nd measurements) of each volunteer for the same variable. This procedure was performed for each one of the $n$ participants and the $n$ averages obtained were summed up and divided by $n$ (total of a number of participants) [22].

Strength of measurements was determined using intraclass correlation (ICC). The values for the reliability

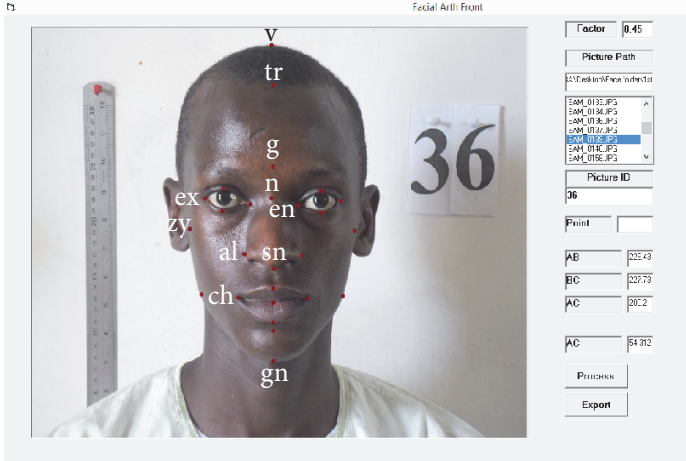

FIGURE 3: Landmarks of the frontal views of the face.

coefficient ranged from 0 to 1 , where ICC $<0$ indicated no reliability, $\geq 0$ but $<0.2$ slight reliability, 0.2 to $<0.4$ fair reliability, 0.4 to $<0.6$ moderate reliability, 0.6 to $<0.8$ substantial reliability, and 1 almost perfect reliability [23].

The interval between two measurements was at least one week and 30 randomly selected records were used for this evaluation.

The data were expressed frequency/percentages. Fisher's Exact (FE) test was used to test for association between variables. SPSS version 20 statistical software was used for the statistical analysis and $P \leq 0.05$ was set as level of significance. 


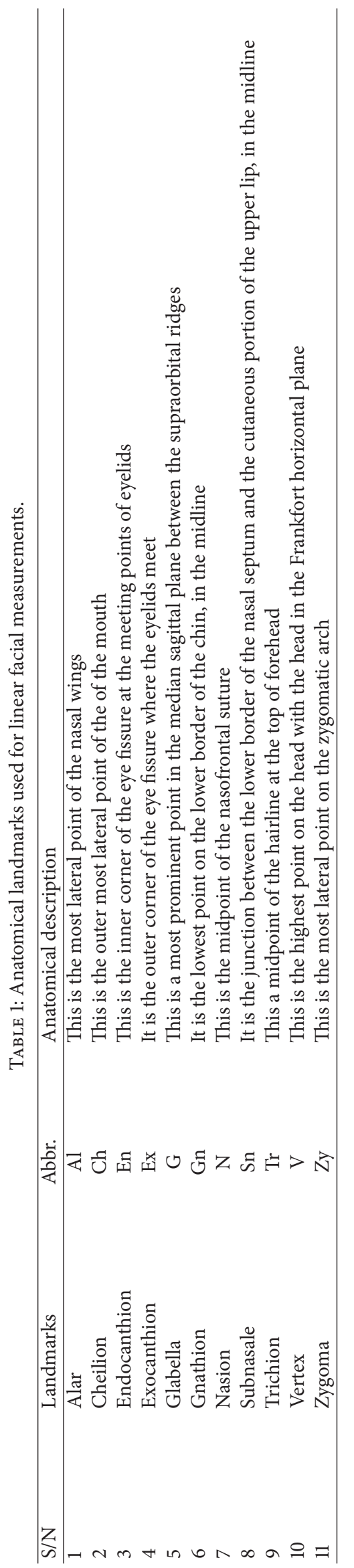


TABLE 2: Linear facial dimensions and ratio with their corresponding landmarks.

\begin{tabular}{lcc}
\hline SN & Facial linear distances & Landmarks \\
\hline 1 & Special head height & v-en \\
2 & Special face height & en-gn \\
3 & Forehead height II & tr-n \\
4 & Nose length & n-sn \\
5 & Lower face height & sn-gn \\
6 & Height of calva & v-tr \\
7 & Forehead height I & tr-g \\
8 & Special upper face height I & g-sn \\
9 & Interocular distance & en-en \\
10 & Nasal width & al-al \\
11 & Upper facial width & zy-zy \\
12 & Mouth width & ch-ch \\
13 & Orbital length & ex-en \\
\hline
\end{tabular}

\section{Results}

Table 4 shows the assessment of error in the variables used in the study. Special head height showed least method error (1.39\%) and higher single measure intraclass correlation (ICC) of 0.98 . The other variables were also within the acceptable level of method error and intraclass correlation.

It was observed that in both sexes there is no occurrence of classical canon of facial proportion. There is also no significant association between sex and facial proportions. However, the female has higher percentages of the variants of the canon compared to the male in all classes of neoclassical facial proportions (Figure 4). A significant association was found in between thumbprint patterns and vertical class III neoclassical facial proportion only when the frequency of both left and right thumbprint patterns was considered a single entity (Table 5). There is no significant association between the thumbprint patterns of the right and left thumbs with vertical horizontal neoclassical facial proportions in male participants (Table 6). Similarly, in female no significant association was found between the horizontal facial proportions and thumbprints patterns in both left and right thumb (Table 7). It was observed that right and left thumbs have more tendency of significance with facial proportion in males and females, respectively.

\section{Discussion}

Evolutionary forces such as genetic drift resulted in reproductive isolation and reduced genetic diversity which may have led to the ethnic variations in the biological traits like facial features and thumbprint patterns. Face and the fingerprint are among the biological features that determine the uniqueness of an individual. In addition, determination of face characteristics from fingerprints is an interesting and attractive idea for applications. This may be considered less technical and inexpensive when the anthropometric approach is adopted especially in the field of clinical and legal practice and human identity. The aim of the study was to
TABLE 3: Nine neoclassical canon facial proportions and their variations.

\begin{tabular}{|c|c|c|}
\hline $\mathrm{SN}$ & Classes & Description \\
\hline \multirow{3}{*}{1} & \multirow{3}{*}{ Class $\mathrm{I}^{\mathrm{a}}$ and its variation } & $\mathrm{SHH}=\mathrm{SFH}$ \\
\hline & & $\mathrm{SHH}>\mathrm{SFH}$ \\
\hline & & $\mathrm{SHH}<\mathrm{SFH}$ \\
\hline \multirow{5}{*}{2} & \multirow{5}{*}{ Class II $^{\mathrm{b}}$ and its variation } & $\mathrm{FH}$ II $=\mathrm{UFH}=\mathrm{LFH}$ \\
\hline & & $\mathrm{UFH}<\mathrm{LFH}$ \\
\hline & & FH II $>$ LFH \\
\hline & & FH II $<$ LFH \\
\hline & & FH II > LFH \\
\hline \multirow{8}{*}{3} & \multirow{8}{*}{ Class III $^{c}$ and its variation } & $\mathrm{HC}=\mathrm{FH} \mathrm{I}=\mathrm{SUFH} \mathrm{I}=\mathrm{LFH}$ \\
\hline & & $\mathrm{HC}<\mathrm{FH} \mathrm{I}$ \\
\hline & & $\mathrm{HC}<\mathrm{SUFH} \mathrm{I}$ \\
\hline & & $\mathrm{HC}<\mathrm{LFH}$ \\
\hline & & $\mathrm{HC}>\mathrm{FH} \mathrm{I}$ \\
\hline & & $\mathrm{FH} \mathrm{I}>\mathrm{SUFH}$ \\
\hline & & FH I $<$ LFH \\
\hline & & SUFH $<$ LFH \\
\hline \multirow{3}{*}{4} & \multirow{3}{*}{ Class $\mathrm{V}^{\mathrm{d}}$ and its variation } & $\mathrm{IOD}=\mathrm{NW}$ \\
\hline & & $\mathrm{IOD}>\mathrm{NW}$ \\
\hline & & IOD $<$ NW \\
\hline \multirow{3}{*}{5} & \multirow{3}{*}{ Class $\mathrm{VI}^{\mathrm{e}}$ and its variation } & $\mathrm{IOD}=\mathrm{OL}$ \\
\hline & & $\mathrm{IOD}>\mathrm{OL}$ \\
\hline & & $\mathrm{IOL}<\mathrm{OL}$ \\
\hline \multirow{3}{*}{6} & \multirow{3}{*}{ Class VII ${ }^{\mathrm{f}}$ and its variation } & $\mathrm{MW}=1.5(\mathrm{NW})$ \\
\hline & & $\mathrm{MW}>1.5(\mathrm{NW})$ \\
\hline & & $\mathrm{MW}<1.5(\mathrm{NW})$ \\
\hline \multirow{3}{*}{7} & \multirow{3}{*}{ Class VIII ${ }^{\mathrm{g}}$ and its variation } & $\mathrm{NW}=0.25(\mathrm{UFW})$ \\
\hline & & $\mathrm{NW}>0.25(\mathrm{UFW})$ \\
\hline & & $\mathrm{NW}<0.25$ (UFW) \\
\hline
\end{tabular}

The superscripts $a, b$, and c indicate two-, three-, and four-section facial profile canon, respectively. The superscripts $\mathrm{d}, \mathrm{e}, \mathrm{f}$, and g indicate orbitonasal, orbital, nasooral, and nasofacial proportion canon, respectively. SHH: special head height, SFH: special face height, FH II: forehead height II, UFH: upper facial height, LFH: lower facial height, HC: height of calva, SUFH I: special upper face height I, FH I: forehead height I, LFH: lower facial height, IOD: interocular distance, NW: nasal width, OL: orbital length, MW: mouth width, and UFW: upper facial width.

determine the pattern on facial proportions base on facial neoclassical canon and also to determine the association between the facial proportions and thumbprints patterns in male and female of Hausa ethnic group.

Among the Hausas, both male and female had no occurrence of classical canon of facial proportions. In other studies, facial canon is present although with low frequency. For example, in Southern Chinese faces Jayaratne et al. [7] reported the frequency of $19 \%$ of orbitonasal canon and $8.7 \%$ in no-oral canon. This may provide the basis of distinction between different ethnic groups. Study on different ethnic group established that the frequency of valid canons was greatly surpassed by their variant. This may promote the idea that other than the canon the variant can be used to compare 
TABLE 4: Assessment of measurement error in paired linear facial dimension and angles.

\begin{tabular}{|c|c|c|c|c|c|}
\hline \multirow{2}{*}{ Variables (mm) } & \multicolumn{3}{|c|}{ Method error } & \multicolumn{2}{|c|}{ Intraclass correlation } \\
\hline & VAV & TEM & Relative TEM (\%) & SM & AM \\
\hline Special head height & 102.88 & 1.43 & 1.39 & 0.98 & 0.99 \\
\hline Special face height & 102.66 & 1.87 & 1.82 & 0.91 & 0.95 \\
\hline Forehead height II & 68.10 & 2.69 & 3.94 & 0.83 & 0.91 \\
\hline Upper facial height & 41.66 & 2.48 & 5.96 & 0.75 & 0.86 \\
\hline Lower facial height & 64.63 & 1.80 & 2.79 & 0.83 & 0.90 \\
\hline Height of calva & 29.25 & 2.04 & 6.96 & 0.94 & 0.97 \\
\hline Forehead height I & 56.39 & 2.92 & 5.17 & 0.80 & 0.89 \\
\hline Special upper facial Height I & 84.35 & 3.36 & 3.98 & 0.49 & 0.66 \\
\hline Interocular distance & 31.41 & 1.30 & 4.14 & 0.77 & 0.87 \\
\hline Nasal width & 41.81 & 1.40 & 3.34 & 0.77 & 0.87 \\
\hline Upper facial width & 123.24 & 2.79 & 2.27 & 0.90 & 0.95 \\
\hline Mouth width & 51.65 & 1.38 & 2.67 & 0.87 & 0.93 \\
\hline Right orbital length & 30.11 & 1.25 & 4.15 & 0.33 & 0.50 \\
\hline Left orbital length & 30.32 & 1.31 & 4.33 & 0.42 & 0.59 \\
\hline
\end{tabular}

VAV: variable average value, TEM: technical error of method, SM: single measures, and AM: average measures.

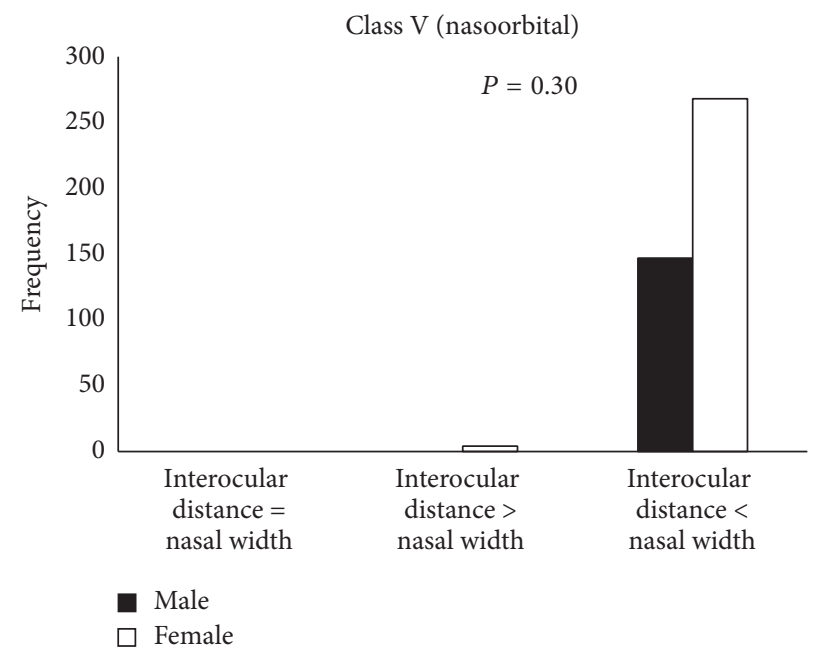

Class VII (nasooral)

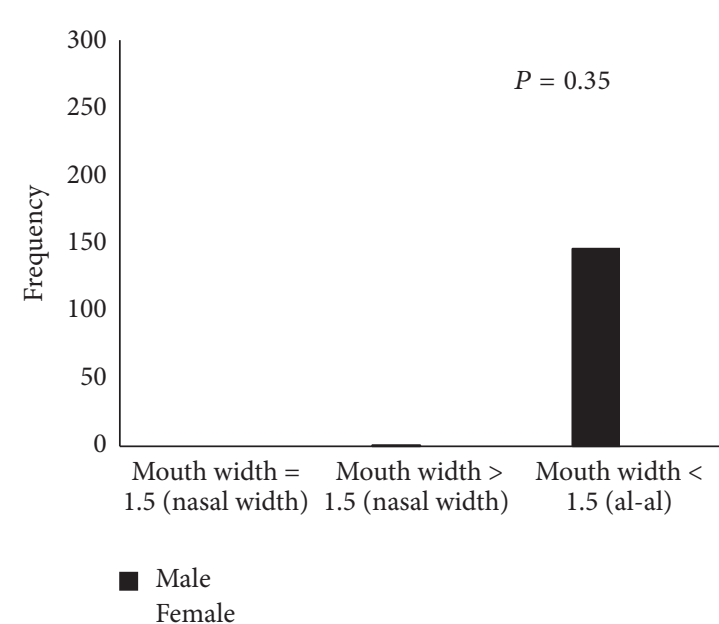

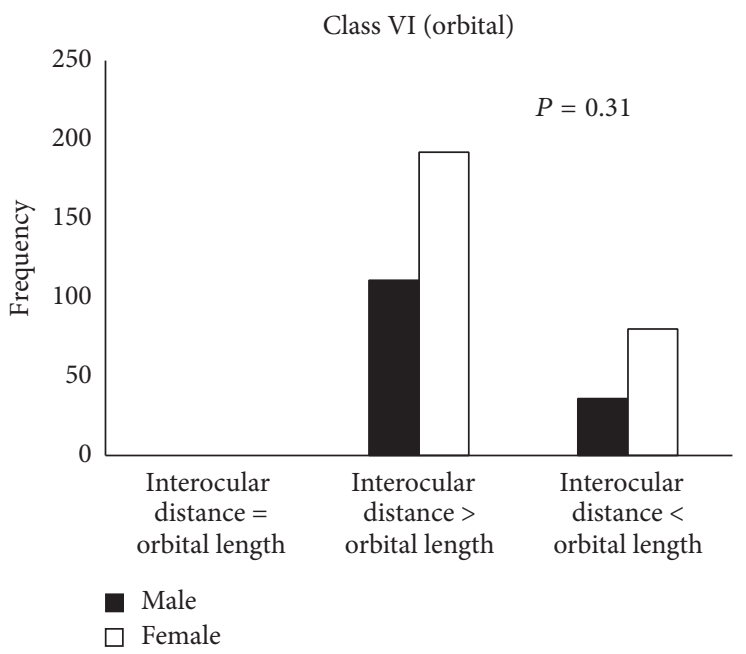

Class VIII (nasofacial)

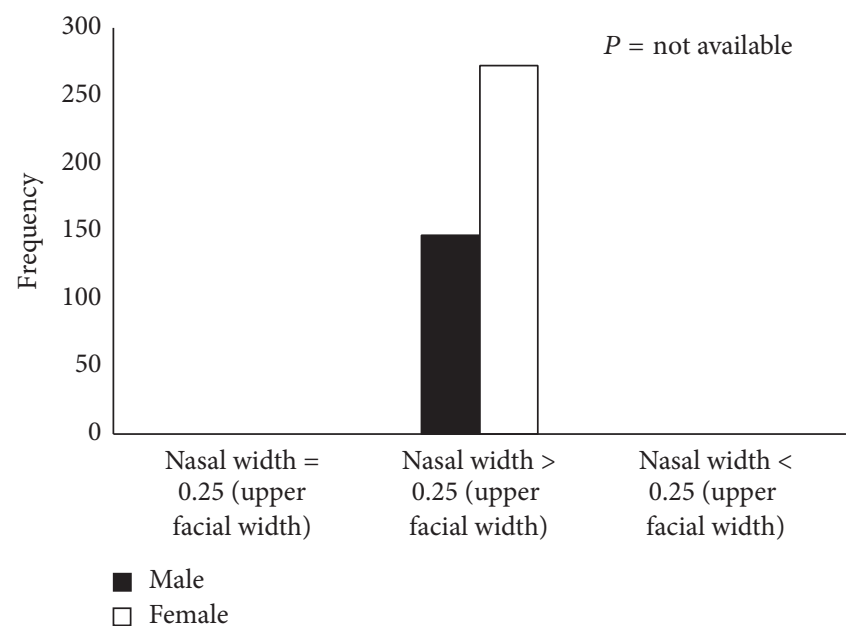

FIgURE 4: Sex differences in class V-VIII (canon and its variants) neoclassical facial proportion. 


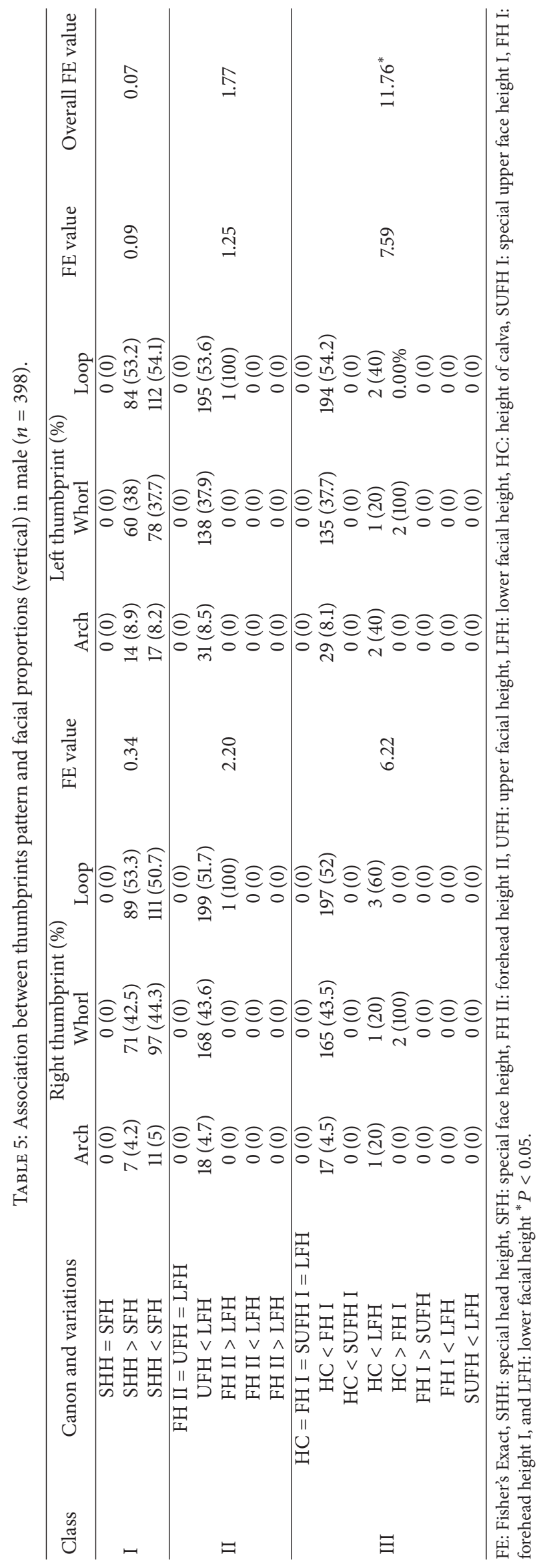




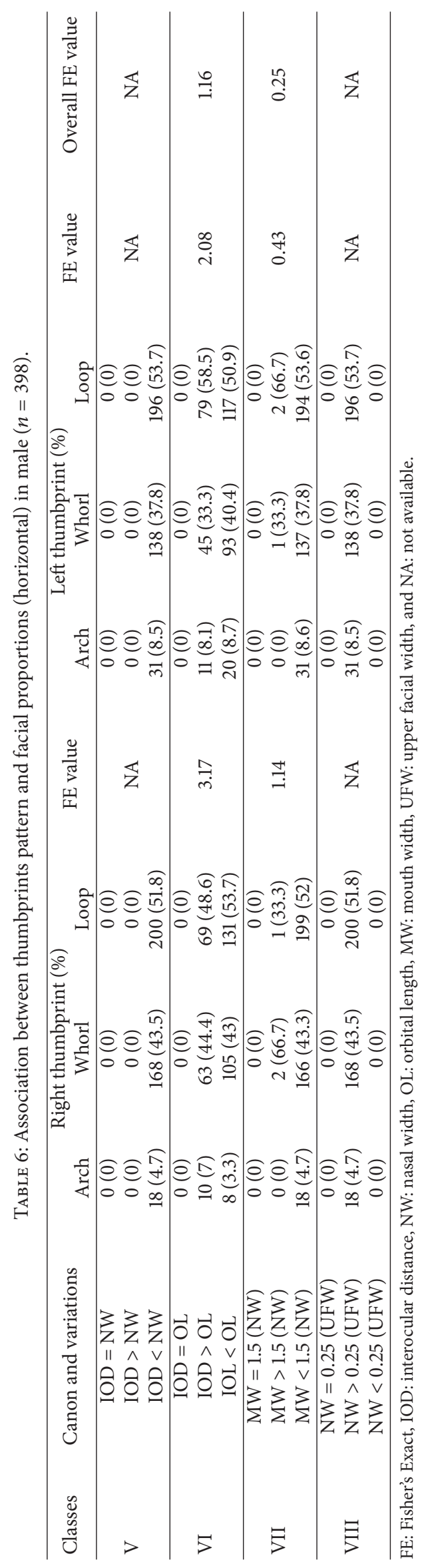




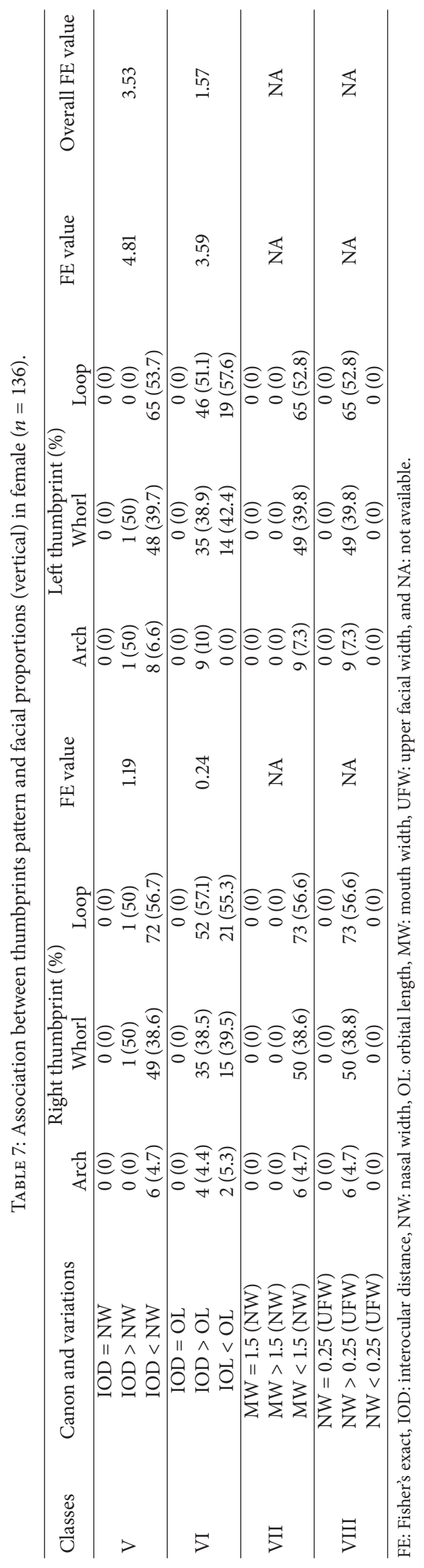


different population and sexes within the same population. Among Hausas, there is no significant association between sex and facial proportions. However, the female has higher percentages of the variant of the canon compared to the male in all classes. In Hong Kong Chinese population the variant in the orbital canon with a wider intercanthal distance was found to be $100 \%$, remarkably higher than $51.5 \%$ observed in North American Caucasians [2]. The frequency of this variant in the Singapore Chinese [3] was similar to the Southern Chinese [7]. A relatively narrow mouth with a wide-nose variant of the nasooral canon was common among all the East Asian ethnic groups and the African Americans [4]. By extension, the variant of the canon may also provide some insight into the population differences.

In contrary to present findings, significant sex differences in relation to the frequency of the orbitonasal canon variant were found among Southern Chinese population [7]. In addition, the comparison between the male and female African American shows the significant different level of occurrence of canon between sexes. In African American male only canons I and VI have been established with the prevalence of $2.8 \%$ and $11.9 \%$, respectively. However, other cannons (II to IX) indicate the dominance of one variant with more than 95\%. But in canon VII, the two variants share the proportions somehow equally [24]. This indicates case sex-specific differences in the occurrence of the cannon. Moreover, based on the literature it can be suggested that ethnic variations exist with respect to different classes of canon. Therefore, the existence of harmonious face is still valid in the world but with sex bias in some population.

From a biological point of view, it is well established that the phenotype of the biological organism was found to be uniquely determined by the interaction of a specific genotype and a specific environment [14]. Physical appearances of faces and fingerprints are also part of an individual's phenotype. In dermatoglyphics studies, like that of the face, the maximum genetic difference between fingerprints has been reported among individuals of a different population. Unrelated persons of the same population have very little genetic similarity in their fingerprints. Parent and child have some genetic similarity as they share half of the genes, siblings have more similarity, and the maximum genetic similarity was documented in the identical twins, which have the closest genetic relationship [25].

In line with the unique characteristic of face and fingerprints of individuals, the present study found a significant association between the thumbprint patterns with facial proportions in male only when the two fingerprints are considered as a single entity. To explain the relationship in different perspective, the previous study analyzing the similarities in fingerprint features in identical twin fingers shows that the fingerprints of identical twins highly correlated as observed in their facial features. In addition to this, other profiles of fingerprints such as ridge count, ridge width, ridge separation, and ridge depth were also found to be significantly correlated in identical twins [14]. The more related the individuals the most similar in appearance they, and vice visa. For example, parent and child have some genetic similarity as they share half of the genes, siblings have more similarity, and the maximum genetic similarity is observed in the identical twins, which bear the closest genetic relationship [26]. Several studies examined the correlation among faces and fingerprints of the identical twins [7, 14, 27, 28]. It was declared that identical twins would cause vulnerability problems in biometrics-based security applications, due to the large correlation among their biometrics. One of the instances was that about $95 \%$ similarity measure of identical twin fingerprints was reported [29]. The same circumstance can be applied to the face. Some of the reason for this high degree similarity includes possession of identical DNA except for the generally undetectable micromutations that begin as soon as the cell starts dividing. Secondly, development of fingerprints and faces of identical twins originate from the same DNA, leading to considerable genetic similarity $[28,30]$. Similarly, the unique identity exhibited by the individual facial expression is also exhibited by fingerprints. Therefore the two traits may share the same intrinsic factor that controls them hence leading to some significance degree of correlation. Genetic studies of both fingerprints pattern and facial morphology suggest a strong influence of genetic factors in the determination of these features. Some genes that were reported to express in low to medium levels in the skin were found to play a key role in the determination of facial feature $[31,32]$. Though the direct information of the influence of the genetic markers on specific fingerprint and facial phenotypes may be a key to revealing the possible relationship that exist between the two features [31, 32]. It might be suggested that the correlation between the fingerprint and facial variables was based on a characteristic of the fingerprints features (quantitative variables) which may be controlled differently from the fingerprint patterns (qualitative variables) during embryogenesis. It may also be suggested that the factors such as volar pad $[33,34]$ and boundary effect among others that determine the pattern of the fingerprints [34] are not the same as factors that determine the other fingerprints features (such as minutiae and ridge thickness) and facial proportions. Thus, the fingerprint pattern and facial features may be controlled by the different mechanism in an individual. Based on the current finding, this study could serve as a preliminary report which needs to be followed up with a broader study that explores more this relationship beyond thumbprints and also includes several other dermatoglyphic variables such as ridge counts, thickness, and minutiae among others.

\section{Conclusion}

Absence of facial canon proportions among Hausa ethnic group and its presence in other population may project the existence of ethnic-specific facial proportions across the continents. There some levels of association between fingerprints and facial proportion. The fingerprint pattern and its associated features may be controlled by a different mechanism such that the two may correlate differently with other features such facial features; however, this may have some level of variations across individual and population. 


\section{Competing Interests}

The authors declare no conflict of interests.

\section{Acknowledgments}

The authors thank all those who volunteered to participate in this research and also Sanusi Aminu who helped in the development of the software used as well as other technical assistance. This work is an extract of a Ph.D. dissertation which was sponsored by Bayero University Research Grant Unit and Tertiary Education Trust (TETFund) of Nigeria.

\section{References}

[1] R. J. Edler, "Background considerations to facial aesthetics," Journal of Orthodontics, vol. 28, no. 2, pp. 159-168, 2001.

[2] L. G. Farkas, T. A. Hreczko, J. C. Kolar, and I. R. Munro, "Vertical and horizontal proportions of the face in young adult North American caucasians: revision of neoclassical canons," Plastic and Reconstructive Surgery, vol. 75, no. 3, pp. 328-337, 1985.

[3] T. T. Le, L. G. Farkas, R. C. K. Ngim, L. S. Levin, and C. R. Forrest, "Proportionality in Asian and North American Caucasian faces using neoclassical facial canons as criteria," Aesthetic Plastic Surgery, vol. 26, no. 1, pp. 64-69, 2002.

[4] L. G. Farkas, C. R. Forrest, and L. Litsas, "Revision of neoclassical facial canons in young adult Afro-Americans," Aesthetic Plastic Surgery, vol. 24, no. 3, pp. 179-184, 2000.

[5] H. Borman, F. Özgür, and G. Gürsu, "Evaluation of soft-tissue morphology of the face in 1,050 young adults," Annals of Plastic Surgery, vol. 42, no. 3, pp. 280-288, 1999.

[6] W. Dawei, Q. Guozheng, Z. Mingli, and L. G. Farkas, "Differences in horizontal, neoclassical facial canons in Chinese (Han) and North American Caucasian populations," Aesthetic Plastic Surgery, vol. 21, no. 4, pp. 265-269, 1997.

[7] Y. S. N. Jayaratne, C. K. Deutsch, C. P. J. McGrath, and R. A. Zwahlen, "Are neoclassical canons valid for southern Chinese faces?" PLoS ONE, vol. 7, no. 12, Article ID e52593, 2012.

[8] L. Buggio, P. Vercellini, E. Somigliana, P. Viganò, M. P. Frattaruolo, and L. Fedele, "You are so beautiful: Behind women's attractiveness towards the biology of reproduction: a narrative review," Gynecological Endocrinology, vol. 28, no. 10, pp. 753757, 2012.

[9] B. M. Reddy, V. P. Chopra, B. Karmakar, K. C. Malhotra, and H. Mueller, "Quantitative dermatoglyphics and population structure in Northwest India," American Journal of Human Biology, vol. 12, no. 3, pp. 315-326, 2000.

[10] B. Karmakar, K. Yakovenko, and E. Kobyliansky, "Sexual dimorphism in the Chuvashian population of Russia in two types of dermatoglyphic traits: principal component analysis," Collegium Antropologicum, vol. 32, no. 2, pp. 467-477, 2008.

[11] N. Özkaya and Ş. Sağiroğlu, "Face recognition from fingerprints," Journal of the Faculty of Engineering and Architecture of Gazi University, vol. 23, no. 4, pp. 785-794, 2008.

[12] D. Maio, D. Maltoni, A. K. Jain, and S. Prabhakar, Handbook of Fingerprint Recognition, Springer, New York, NY, USA, 2003.

[13] L. C. Jain, U. Halici, I. Hayashi, S. B. Lee, and S. Tsutsui, Intelligent Biometric Techniques in Fingerprint and Face Recognition, CRC Press, New York, NY, USA, 1999.

[14] A. K. Jain, S. Prabhakar, and S. Pankanti, "On the similarity of identical twin fingerprints," Pattern Recognition, vol. 35, no. 11, pp. 2653-2663, 2002.
[15] N. E. Lenshie and F. E. F. Ayokhai, "Rethinking pre-colonial state formation and ethno-religious identity transformation in hausaland under the sokoto caliphate," Global Journal of Human Social Science Political Science, vol. 13, no. 4, pp. 1-10, 2013.

[16] A. S. Barau, "The great attractions of kano," in Research and Documentation publications. Research and Documentation Directorate, Government House Kano, 2007.

[17] C. F. A. Moorrees, "Natural head position-a revival," American Journal of Orthodontics and Dentofacial Orthopedics, vol. 105, no. 5, pp. 512-513, 1994.

[18] V. F. Ferrario, C. Sforza, A. Miani, and G. Tartaglia, "Craniofacial morphometry by photographic evaluations," American Journal of Orthodontics and Dentofacial Orthopedics, vol. 103, no. 4, pp. 327-337, 1993.

[19] L. G. Farkas, "Examination," in Anthropometry of the Head and Face, L. G. Farkas, Ed., pp. 3-56, Raven Press, New York, NY, USA, 2nd edition, 1994.

[20] J. P. Porter and K. L. Olson, "Anthropometric facial analysis of the African American woman," Archives of Facial Plastic Surgery, vol. 3, no. 3, pp. 191-197, 2001.

[21] D. Gibelli, A. Mapelli, Z. Obertovà et al., "Age changes of facial measurements in European young adult males: implications for the identification of the living," HOMO-Journal of Comparative Human Biology, vol. 63, no. 6, pp. 451-458, 2012.

[22] T. A. Perini, G. L. Oliveira, J. S. Ornellas, and F. P. de Oliveira, "Technical error of measurement in anthropometry," Revista Brasileira de Medicina do Esporte, vol. 11, no. 1, pp. 86-90, 2005.

[23] P. E. Shrout and J. L. Fleiss, "Intraclass correlations: uses in assessing rater reliability," Psychological Bulletin, vol. 86, no. 2, pp. $420-428,1979$.

[24] J. P. Porter, "The average African American male face: an anthropometric analysis," Archives of Facial Plastic Surgery, vol. 6, no. 2, pp. 78-81, 2004.

[25] H. Cummins and C. Midlo, Fingerprints, Palms and Soles: An Introduction to Dermatoglyphics, Dover Publications Inc., New York, NY, USA, 1961.

[26] S. Sagiroglu and N. Ozkaya, "An intelligent face features generation system from fingerprints," Turkish Journal of Electrical Engineering and Computer, vol. 17, no. 2, 2009.

[27] A. W.-K. Kong, D. Zhang, and G. Lu, "A study of identical twins' palmprints for personal verification," Pattern Recognition, vol. 39, no. 11, pp. 2149-2156, 2006.

[28] A. Jain, S. Prabhakar, and S. Pankanti, "Twin test: on discriminability of fingerprints," in Audio- and Video-Based Biometric Person Authentication, vol. 2091 of Lecture Notes in Computer Science, pp. 211-217, Springer, Berlin, Germany, 2001.

[29] D. F. Costello, "The perfect deception: identical twins," Wall Street Journal, vol. 233, no. 28, B1, B4, 1999.

[30] W. Bodmer and R. McKie, The Book of Man: The Quest to Discover Our Genetic Heritage, Abacus, London, UK, 1994.

[31] P. Claes, D. K. Liberton, K. Daniels et al., "Modeling 3D facial shape from DNA," PLoS Genetics, vol. 10, no. 3, Article ID e1004224, 2014.

[32] Y. Y. Ho, D. M. Evans, G. W. Montgomery et al., "Common genetic variants influence whorls in fingerprint patterns," Journal of Investigative Dermatology, vol. 136, no. 4, pp. 859-862, 2016.

[33] J. Mulvihill and D. W. Smith, "The genesis of dermatoglyphics," The Journal of Pediatrics, vol. 75, no. 4, pp. 579-589, 1969.

[34] M. Kücken and A. C. Newell, "Fingerprint formation," Journal of Theoretical Biology, vol. 235, no. 1, pp. 71-83, 2005. 


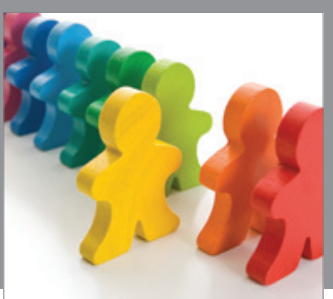

Autism

Research and Treatment
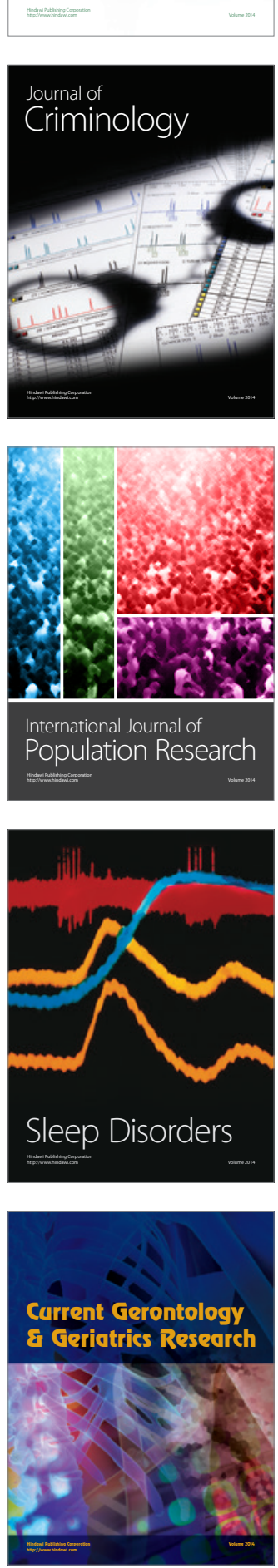

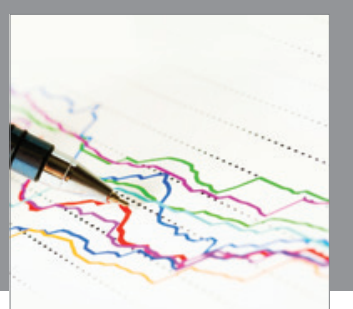

Economics

Research International
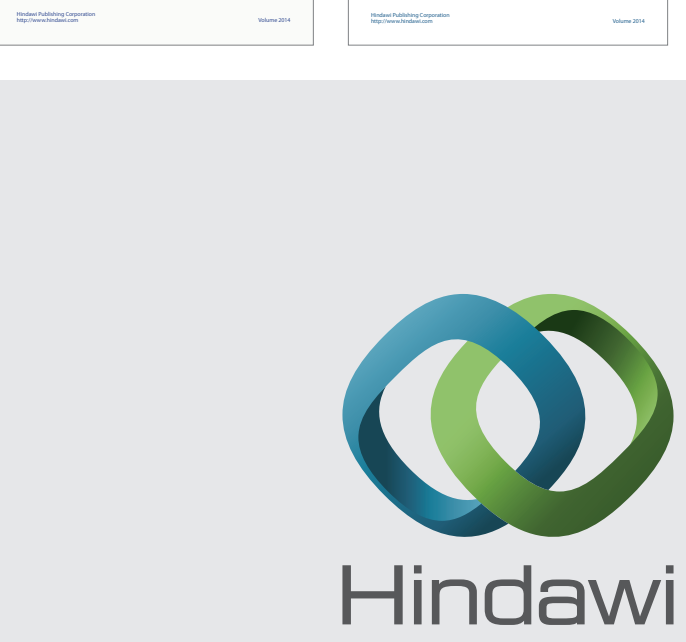

Submit your manuscripts at

https://www.hindawi.com
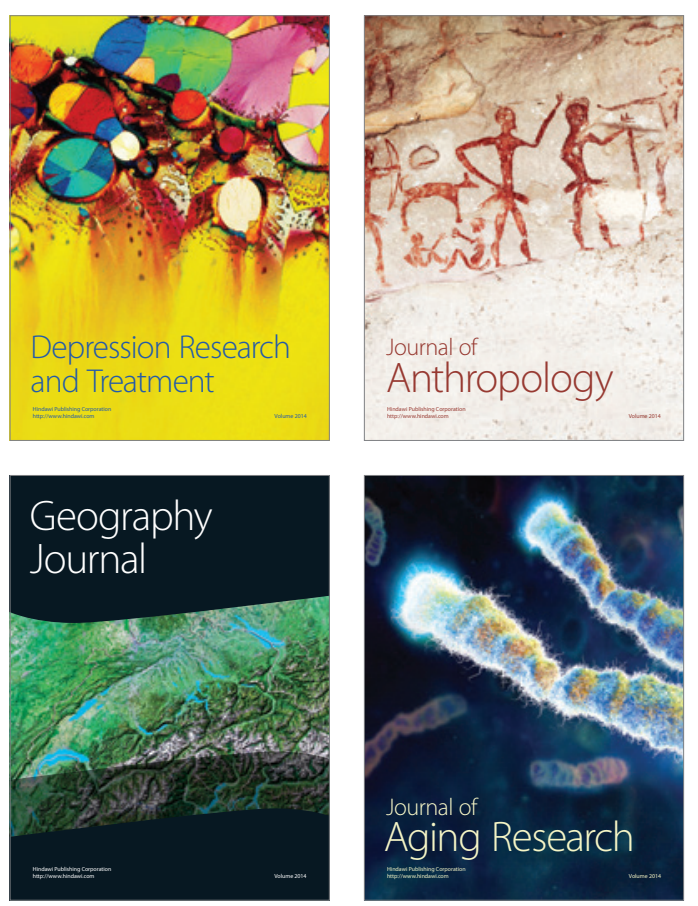
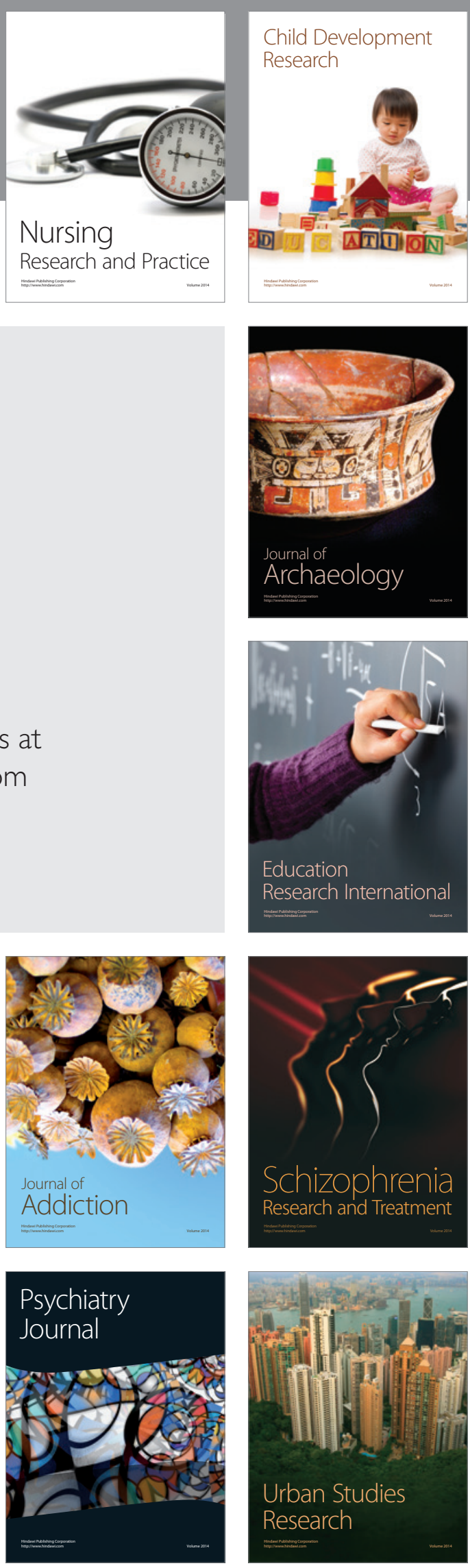